\title{
Self reported alcohol intake in pregnancy: comparison between four methods
}

\author{
U Kesmodel, S F Olsen
}

\begin{abstract}
Study objective-To assess the agreement between four different measures of alcohol intake in pregnancy.

Design and setting-Danish speaking pregnant women referred to the Midwife Centre in Aarhus, Denmark, for routine antenatal care were contacted at their first visit at approximately 15-16 weeks gestation from October to December 1998. The women were interviewed about current average alcohol intake and intake within the previous week, and subsequently filled in a two week diary on alcohol intake. When booking for delivery at the end of the first trimester the women were also asked to complete a questionnaire including a one item question on current average alcohol intake.
\end{abstract}

Participants-Participants were 441 pregnant women.

Main results-Per cent agreement \pm 1 category ranged between 73 and 82 . Mean (SD) intake ranged between 1.09 (1.35) drinks/week for diaries, and $0.69(0.85)$ for questionnaires. Mean differences between methods were all close to zero. Three of the four measures yielded comparable distributions of average alcohol intake, but reports of intake within the past seven days seemed to be an inappropriate measure of average intake, yielding three times as many abstainers as expected when combining the methods.

Conclusions-When assessing the distribution of alcohol intake in pregnancy or when studying adverse pregnancy outcomes that are probably caused mainly by sustained exposure it seems that for pregnant women with low to moderate alcohol intake diaries or an average measure from interviews or a simple one item questionnaire may be applied. A measure of intake for the previous week seems to be a relevant measure only when studying adverse pregnancy outcomes that are most probably caused by binge-like exposure.

(F Epidemiol Community Health 2001;55:738-745)

Science Centre,

Statens Serum

Institut, Copenhagen,

Denmark

S F Olsen

Correspondence to:

Dr Kesmodel

(skejuk@au.dk)

Accepted for publication 26 March 2001 therefore needed. An important element in this research is to develop reliable methods to assess alcohol intake. Information on alcohol intake in pregnancy is mostly collected through the use of self administered questionnaires ${ }^{3}$ or interviews, either face to face ${ }^{4}$ or by telephone. ${ }^{5}$ Although the majority of studies among pregnant women use prospectively collected information on alcohol intake few studies have compared prospective information obtained from different methods. Only a few studies have compared interviews with questionnaires,${ }^{67}$ and the results have been inconsistent. Among men and non-pregnant women diaries have been shown to yield higher reports of intake than questionnaires, ${ }^{8-10}$ but to our knowledge diaries have never been used among pregnant women.

In a representative sample of pregnant Danish women with low to moderate alcohol consumption we assessed the agreement between four different measures of alcohol intake using diaries, two measures obtained from interviews, and questionnaires.

\section{Methods}

SETTING

All pregnant women in Denmark are offered free antenatal care including a number of visits in the antenatal care centre run by midwives. Almost all women in Denmark participate in the antenatal care programme. Danish speaking pregnant women $(n=478)$ referred to the Midwife Centre in Aarhus, Denmark, for routine antenatal care were contacted at their first visit during a two month period from 15 October until 17 December 1998.

\section{DATA COLLECTION}

The study consisted of an interview mainly concerned with drinking habits, knowledge about and attitudes towards alcohol intake during pregnancy. Questions were asked about current average weekly intake of different types of alcohol containing beverages (interview ${ }_{\mathrm{a}}$ ) (see appendix 1 for details). Questions included non-alcoholic wine and beer in order to improve information retrieval and avoid misclassification of non-alcoholic beverages as alcohol containing beverages. Questions on current intake were followed by questions on intake during the week before the interview $\left(\right.$ interview $_{7}$ ) (appendix 1). Interviews were performed face to face by two specially trained midwives either immediately after the first antenatal care visit or, if this was not possible, on a day of the woman's own choice as soon as possible after the visit. 


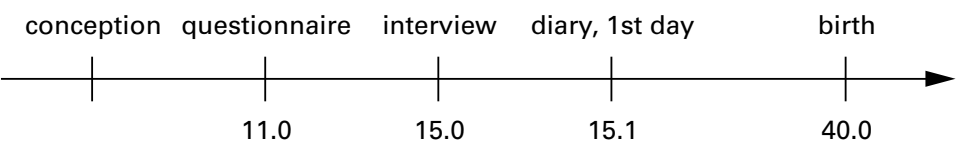

Median gestational age (week)

Figure 1 Median gestational age when filling in the questionnaire, at the time of interview, and on the first day of filling in the diary, Aarhus, Denmark, 1998.

The women were subsequently asked to fill in a diary on alcohol intake during two consecutive weeks starting immediately after the interview. Each page in the diary represented one day, and for each day the woman was to note the number of drinks for each alcohol category and the time of day in a preprinted table (see appendix 2 for details). At the end of the diary the woman was asked if she believed she had changed her drinking habits since the interview. A stamped envelope was handed out together with the diary. If the diary had not been returned within four weeks after the interview, the woman was contacted by telephone and reminded to return the diary. Results from the diary are presented as an average of the two week period where not otherwise stated.

The Midwife Centre in Aarhus is associated with the Department of Obstetrics and Gynaecology, Aarhus University Hospital. When booking for delivery at the end of the first trimester women are asked to fill in a self administered questionnaire for the medical record and a research questionnaire. The self administered questionnaire asked a single question about average current maternal alcohol intake without specifying subtypes of alcohol (see appendix 1), smoking habits before pregnancy and currently, maternal height, prepregnant weight, parity, chronic diseases, and the use of medication within the last three months before pregnancy. The question on alcohol is the standard measurement used for clinical purposes in the department. For calculating mean deviations from the methods described above the mean of each category was used for the questionnaire $(0,0.5,1,2$, $3.5,7$, etc.). The research questionnaire provided information on marital status and occupational status.

Median gestational age when filling in the questionnaire, at the time of interview, and on the first day of filling in the diary were as shown in figure 1.

The definition of a drink followed the definition from the Danish National Board of Health, one drink containing $12 \mathrm{~g}$ or $15 \mathrm{ml}$ of pure alcohol, the equivalent of one normal beer, one glass of wine, $8 \mathrm{cl}$ of fortified wine, or $4 \mathrm{cl}$ of spirits. For comparison, one drink in Britain contains $8 \mathrm{~g}$ of pure alcohol, ${ }^{1}$ and the definition varies between countries. ${ }^{11}$ In recent years the strength of beer (as measured both in volume $\%$ and number of drinks: $0.5,1,1.5$, etc) has been written on the label of each bottle in Denmark. Nonalcoholic beverages were coded as zero, light beer as half a drink, and strong beer as 1.5 drinks.

\section{STUDY POPULATION}

Of the 478 women invited to participate in the study 441 agreed to do so. Characteristics of participants and non-participants can be seen in table 1 . Subsequently two interview questionnaires were lost before data entry and could not be recovered leaving 439 interviews for analysis. Eighty nine per cent of the interviews were performed before 19 completed weeks of gestation. A total of 434 women returned the diary. Eighty five per cent of diaries were returned within four weeks following the interview. Information from both interview and diary was available for 432 women $(90 \%)$. Of the 441 women alcohol information from the routine questionnaire was available for 414 . For the participants who were interviewed but did not return the questionnaire values for the variables in table 1 did not differ appreciably on inspection (information on smoking before pregnancy not available).

Table 1 Characteristics of participants and non-participants, pregnant women attending routine antenatal care. Aarhus, Denmark, 1998

\begin{tabular}{|c|c|c|}
\hline & $\begin{array}{l}\text { Participants } \\
(n=441)\end{array}$ & $\begin{array}{l}\text { Non-participants } \\
(n=37)\end{array}$ \\
\hline Mean age (SD) & $30.0(4.5)$ & $30.2(6.2)$ \\
\hline Mean prepregnancy body mass index $(\mathrm{SD})^{\star}$ & $23.0(3.7)$ & $23.0(4.7)$ \\
\hline Mean number of cigarettes/day (SD) (among smokers before pregnancy) $\dagger$ & $12(6.3)$ & $13(4.8)$ \\
\hline Mean number of cigarettes/day (SD) (among current smokers) $\ddagger$ & $7(4.3)$ & $10(5.8)$ \\
\hline Median gestational age (weeks) at interview/enrolment $\$$ & 15.0 & 15.4 \\
\hline Median gestational age (weeks) when filling in the questionnaire & 11.0 & 11.3 \\
\hline Mean birthweight of child, grammes (SD) & $3551(577)$ & $3599(504)$ \\
\hline Mean length of child at birth, $\mathrm{cm}(\mathrm{SD})$ & $51.8(2.8)$ & $51.9(1.9)$ \\
\hline Mean gestational age (weeks) at delivery (SD) & $39.6(2.0)$ & $39.6(1.6)$ \\
\hline Smokers (before pregnancy)\# & $32 \%$ & $30 \%$ \\
\hline Smokers (current) $\ddagger$ & $17 \%$ & $22 \%$ \\
\hline 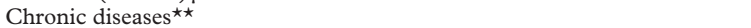 & $7 \%$ & $5 \%$ \\
\hline Used medicine within past 3 months before pregnancyt† & $27 \%$ & $22 \%$ \\
\hline 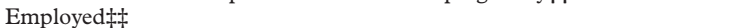 & $67 \%$ & $66 \%$ \\
\hline Studentsł‡ & $18 \%$ & $20 \%$ \\
\hline
\end{tabular}

*Information missing for one participant. HInformation missing for six smokers (five participants, one non-participant). \#Information missing for seven participants. \Information missing for two non-participants. "Live, singleton births only. \#Information missing for 22 participants. ${ }^{\star \star}$ Hypertension, diabetes, epilepsy, rheumatism, arthritis, heart, lung, metabolic, or kidney disease. $+\dagger$ Information missing for two participants. $\neq$ Information missing for six participants and two non-participants. 
Table 2 Association between four different measures of total alcohol intake during

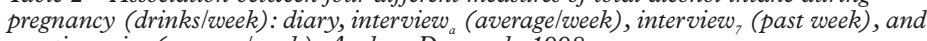
questionnaire (average/week). Aarhus, Denmark, 1998

\begin{tabular}{|c|c|c|c|c|c|c|c|c|c|}
\hline & \multicolumn{8}{|c|}{ Diary (drinks/week) } & \multirow[b]{2}{*}{ Total } \\
\hline & 0 & $<1$ & 1 & 2 & $3-4$ & $5-9$ & $10-14$ & Missing & \\
\hline \multicolumn{10}{|c|}{ Interview (drinks/week) } \\
\hline 0 & 92 & 29 & 3 & 0 & 1 & 0 & 0 & 4 & 129 \\
\hline$<1$ & 18 & 35 & 22 & 19 & 9 & 1 & 0 & 0 & 104 \\
\hline 1 & 11 & 19 & 20 & 27 & 6 & 2 & 0 & 1 & 86 \\
\hline 2 & 6 & 20 & 14 & 24 & 10 & 2 & 0 & 0 & 76 \\
\hline $3-4$ & 0 & 2 & 2 & 12 & 16 & 4 & 0 & 2 & 38 \\
\hline $5-9$ & 0 & 0 & 0 & 1 & 2 & 2 & 1 & 0 & 6 \\
\hline $10-14$ & 0 & 0 & 0 & 0 & 0 & 0 & 0 & 0 & 0 \\
\hline Missing & 0 & 1 & 1 & 0 & 0 & 0 & 0 & 0 & 2 \\
\hline Total & 127 & 106 & 62 & 83 & 44 & 11 & 1 & 7 & 441 \\
\hline \multicolumn{10}{|c|}{ Interview. (drinks/week) } \\
\hline 0 & 113 & 50 & 25 & 23 & 13 & 2 & 0 & 4 & 230 \\
\hline$<1$ & 7 & 11 & 5 & 6 & 2 & 0 & 0 & 0 & 31 \\
\hline 1 & 4 & 27 & 20 & 32 & 8 & 3 & 0 & 2 & 96 \\
\hline 2 & 2 & 13 & 7 & 12 & 12 & 3 & 0 & 0 & 49 \\
\hline $3-4$ & 1 & 4 & 4 & 9 & 7 & 2 & 1 & 1 & 29 \\
\hline $5-9$ & 0 & 0 & 0 & 1 & 2 & 1 & 0 & 0 & 4 \\
\hline $10-14$ & 0 & 0 & 0 & 0 & 0 & 0 & 0 & 0 & 0 \\
\hline Missing & 0 & 1 & 1 & 0 & 0 & 0 & 0 & 0 & 2 \\
\hline Total & 127 & 106 & 62 & 83 & 44 & 11 & 1 & 7 & 441 \\
\hline \multicolumn{10}{|c|}{ Questionnaire (drinks/week) } \\
\hline 0 & 79 & 20 & 6 & 2 & 4 & 0 & 0 & 2 & 113 \\
\hline$<1$ & 36 & 62 & 39 & 42 & 9 & 3 & 0 & 0 & 191 \\
\hline 1 & 3 & 11 & 8 & 19 & 14 & 1 & 0 & 1 & 57 \\
\hline 2 & 2 & 3 & 6 & 12 & 8 & 2 & 0 & 1 & 34 \\
\hline $3-4$ & 0 & 2 & 0 & 2 & 7 & 4 & 1 & 1 & 17 \\
\hline $5-9$ & 1 & 0 & 0 & 0 & 0 & 0 & 0 & 0 & 1 \\
\hline $10-14$ & 0 & 0 & 0 & 0 & 0 & 0 & 0 & 0 & 0 \\
\hline Missing & 6 & 8 & 3 & 6 & 2 & 1 & 0 & 2 & 28 \\
\hline Total & 127 & 106 & 62 & 83 & 44 & 11 & 1 & 7 & 441 \\
\hline
\end{tabular}

\begin{tabular}{llllllll}
\hline \multicolumn{2}{l}{ Interview $_{a}$ (drinks/week) } \\
\cline { 2 - 6 } & $<1$ & 1 & 2 & $3-4$ & $5-9$ & Missing & Total \\
\hline
\end{tabular}

\begin{tabular}{|c|c|c|c|c|c|c|c|c|}
\hline \multicolumn{9}{|c|}{ Interview $_{7}$ (drinks/week) } \\
\hline 0 & 119 & 59 & 31 & 16 & 5 & 0 & 0 & 230 \\
\hline$<1$ & 3 & 17 & 5 & 4 & 2 & 0 & 0 & 31 \\
\hline 1 & 4 & 23 & 34 & 25 & 8 & 2 & 0 & 96 \\
\hline 2 & 1 & 4 & 12 & 21 & 11 & 0 & 0 & 49 \\
\hline $3-4$ & 2 & 1 & 3 & 9 & 11 & 3 & 0 & 29 \\
\hline $5-9$ & 0 & 0 & 1 & 1 & 1 & 1 & 0 & 4 \\
\hline Missing & 0 & 0 & 0 & 0 & 0 & 0 & 2 & 2 \\
\hline Total & 129 & 104 & 86 & 76 & 38 & 6 & 2 & 441 \\
\hline \multicolumn{9}{|c|}{ Questionnaire (drinks/week) } \\
\hline 0 & 87 & 18 & 4 & 3 & 0 & 0 & 1 & 113 \\
\hline$<1$ & 31 & 60 & 54 & 40 & 4 & 1 & 1 & 191 \\
\hline 1 & 1 & 13 & 18 & 14 & 11 & 0 & 0 & 57 \\
\hline 2 & 2 & 3 & 4 & 12 & 12 & 1 & 0 & 34 \\
\hline $3-4$ & 0 & 1 & 1 & 2 & 9 & 4 & 0 & 17 \\
\hline $5-9$ & 1 & 0 & 0 & 0 & 0 & 0 & 0 & 1 \\
\hline Missing & 7 & 9 & 5 & 5 & 2 & 0 & 0 & 28 \\
\hline Total & 129 & 104 & 86 & 76 & 38 & 6 & 2 & 441 \\
\hline
\end{tabular}

\begin{tabular}{lllllllll}
\hline \multicolumn{7}{c}{} & \multicolumn{2}{l}{ Interview $_{7}$ (drinks/week) } \\
\cline { 2 - 6 } & 0 & $<1$ & 1 & 2 & $3-4$ & $5-9$ & Missing & Total \\
\hline \multicolumn{2}{l}{ Questionnaire (drinks/week) } & & & & & & \\
0 & 95 & 6 & 8 & 2 & 1 & 0 & 1 & 113 \\
$<1$ & 94 & 14 & 49 & 22 & 10 & 1 & 1 & 191 \\
1 & 18 & 4 & 18 & 12 & 4 & 1 & 0 & 57 \\
2 & 7 & 4 & 8 & 6 & 7 & 2 & 0 & 34 \\
$3-4$ & 1 & 0 & 5 & 5 & 6 & 0 & 0 & 17 \\
$5-9$ & 1 & 0 & 0 & 0 & 0 & 0 & 0 & 1 \\
Missing & 14 & 3 & 8 & 2 & 1 & 0 & 0 & 28 \\
Total & 230 & 31 & 96 & 49 & 29 & 4 & 2 & 441 \\
\hline
\end{tabular}

STATISTICAL METHODS

Various statistical measurements have been recommended for assessing validity, reliability and reproducibility of epidemiological tools. $^{12-14}$ Following Bellach ${ }^{14}$ and our own previous assessment of self reported smoking habits, ${ }^{15}$ we present the results of various statistics: Agreement between methods was evaluated by calculating per cent complete agreement $\left(P_{0}\right)$ and per cent agreement \pm 1 category $\left(P_{1}\right)$ as is often used in nutritional epidemiology, ${ }^{16}$ and mean differences between methods. We subsequently performed multiple linear regression analyses to see if the differences between methods could be explained by a number of maternal characteristics: We used the difference between methods as dependent variable, and included as independent variables current smoking habits, age, prepregnancy body mass index, parity, marital status (married/cohabiting; single), and occupational status (employed; unemployed; rehabilitation/social security; student; other). Regression analyses were performed first for all women together, and subsequently for each type of alcohol. Agreement was visualised as recommended by Bland and Altman. ${ }^{13} \mathrm{We}$ evaluated the association between methods by calculating correlation coefficients (Spearman's $\rho, r_{s}$ ).

The study was approved by the regional ethics committee, and the Danish Data Protection Agency.

\section{Results}

For diary, interview ${ }_{\mathrm{a}}$, interview ${ }_{7}$, and questionnaire overall mean (SD) intake was 1.09 (1.35), 0.96 (1.03), 0.74 (1.12), and 0.69 (0.85) drinks/week, respectively, and for women claiming not to be abstainers mean (SD) intake was 1.55 (1.36), 1.36 (0.98), 1.56 (1.17), and $0.96(0.86)$ drinks/week, respectively. Total alcohol intake was comprised of $70 \%$ wine, $23 \%$ beer, $4 \%$ fortified wine, and $3 \%$ spirits in the diary; $59 \%$ wine, $26 \%$ beer, $8 \%$ fortified wine, and $8 \%$ spirits in interview $_{\mathrm{a}}$; and $73 \%$ wine, $19 \%$ beer, $4 \%$ fortified wine, and $3 \%$ spirits in interview . For $_{7}$ total alcohol intake per cent agreement \pm 1 category ranged between 73 and 82 (tables 2 and 3 ).

Alcohol intake seemed to be systematically underreported in interview ${ }_{\mathrm{a}}$, interview $_{7}$, and the questionnaire compared with the diary (fig 2 ), whereas this was not the case for comparisons between the other methods.

For subtypes of alcohol agreement was good for beer and wine (table 3). For fortified wine and spirits agreement measured by mean difference and per cent agreement was good due to many abstainers, but poor as measured by correlation coefficients due to substantial disagreement between methods for nonabstainers (table 3).

Mean differences were all close to zero (table 3). Restricting analyses to women who were not abstainers, or to women who claimed not to have changed their drinking habits after the interview did not change this conclusion. In multiple linear regression analyses there was a tendency towards increasing difference in total intake between the diary and the other measures with increasing number of cigarettes smoked ( $p$ values for the regression coefficients for smoking were 0.06 for diary versus interview $_{\mathrm{a}}, 0.02$ for diary versus interview $_{7}$, and 0.04 for diary versus questionnaire). This was attributable to increasing 
Table 3. Mean differences (SD) and per cent (proportion of) agreement between and correlation coefficients (Spearman's $\rho, r_{s s}$ ) for the associations between four different measures of alcohol intake during pregnancy (drinks/week): diary, interview

(average/week), interview, (past week), and questionnaire*. All differences calculated as: first method — second method mentioned. Aarhus, Denmark, 1998

\begin{tabular}{|c|c|c|c|c|c|}
\hline & Number & Mean $(S D)$ & $P_{0} t$ & $P_{1} \neq$ & $r_{s}$ \\
\hline \multicolumn{6}{|c|}{ Diary versus interview $_{a}$} \\
\hline Total & 432 & $0.14(1.10)$ & 0.44 & 0.80 & 0.66 \\
\hline Beer & 432 & $0.02(0.55)$ & 0.65 & 0.93 & 0.46 \\
\hline Wine & 432 & $0.19(0.82)$ & 0.50 & 0.85 & 0.68 \\
\hline Fortified wine & 432 & $-0.03(0.25)$ & 0.85 & 0.99 & 0.22 \\
\hline Spirits & 432 & $-0.03(0.24)$ & 0.83 & 0.99 & 0.14 \\
\hline \multicolumn{6}{|c|}{ Diary versus interview $_{7}$} \\
\hline Total & 432 & $0.35(1.33)$ & 0.38 & 0.73 & 0.51 \\
\hline Beer & 432 & $0.12(0.64)$ & 0.69 & 0.90 & 0.31 \\
\hline Wine & 432 & $0.21(1.02)$ & 0.45 & 0.77 & 0.49 \\
\hline Fortified wine & 432 & $0.01(0.25)$ & 0.89 & 0.98 & 0.13 \\
\hline Spirits & 432 & $0.02(0.22)$ & 0.91 & 0.98 & 0.02 \\
\hline \multicolumn{6}{|c|}{ Diary versus questionnaire } \\
\hline Total & 408 & $0.41(1.16)$ & 0.41 & 0.77 & 0.60 \\
\hline \multicolumn{6}{|c|}{ Interview $_{\mathrm{a}}$ versus interview ${ }_{7}$} \\
\hline Total & 439 & $0.22(0.98)$ & 0.46 & 0.81 & 0.63 \\
\hline Beer & 439 & $0.11(0.47)$ & 0.73 & 0.94 & 0.53 \\
\hline Wine & 439 & $0.03(0.68)$ & 0.51 & 0.89 & 0.64 \\
\hline Fortified wine & 439 & $0.04(0.20)$ & 0.87 & 0.99 & 0.33 \\
\hline Spirits & 439 & $0.05(0.22)$ & 0.87 & 0.99 & 0.27 \\
\hline \multicolumn{6}{|c|}{ Interview $_{\mathrm{a}}$ versus questionnaire } \\
\hline Total & 411 & $0.27(0.85)$ & 0.45 & 0.82 & 0.67 \\
\hline \multicolumn{6}{|c|}{ Interview $_{7}$ versus questionnaire } \\
\hline Total & 411 & $0.06(1.12)$ & 0.34 & 0.79 & 0.48 \\
\hline
\end{tabular}

*The questionnaire did not comprise information on different types of alcohol. $+\mathrm{P}_{0}$ : per cent complete agreement. $\ddagger \mathrm{P}_{1}$ : per cent agreement \pm 1 category.

Table 4 Frequency of alcohol consumption as reported in two week diaries. Intake during week 1 compared with week 2. Numbers are number of women (row per cent). Aarhus, Denmark, 1998

\begin{tabular}{|c|c|c|c|c|c|c|c|}
\hline & \multicolumn{7}{|c|}{ Week 2 in diary } \\
\hline & 0 & $<1$ & 1 & 2 & $3-4$ & $\geqslant 5$ & Total \\
\hline \multicolumn{8}{|c|}{ Week 1 in diary } \\
\hline 0 & $127(60.2)$ & $31(14.7)$ & $24(11.4)$ & $15(7.1)$ & $14(6.6)$ & $0(0.0)$ & $211(100.0)$ \\
\hline$<1$ & $15(44.1)$ & $6(17.6)$ & $6(17.6)$ & $4(11.8)$ & $2(5.9)$ & $1(2.9)$ & $34(100.0)$ \\
\hline 1 & $11(22.9)$ & $4(8.3)$ & $14(29.2)$ & $11(22.9)$ & $7(14.6)$ & $1(2.1)$ & $48(100.0)$ \\
\hline 2 & $16(22.2)$ & $3(4.2)$ & $14(19.4)$ & $25(34.7)$ & $9(12.5)$ & $5(6.9)$ & $72(100.0)$ \\
\hline $3-4$ & $7(13.7)$ & $6(11.8)$ & $7(13.7)$ & $11(21.6)$ & $12(23.5)$ & $8(15.7)$ & $51(100.0)$ \\
\hline$\geqslant 5$ & $1(5.6)$ & $0(0.0)$ & $3(16.7)$ & $3(16.7)$ & $5(27.8)$ & $6(33.3)$ & $18(100.0)$ \\
\hline Total & $177(40.8)$ & $50(11.5)$ & $68(15.7)$ & $69(15.9)$ & 49 (11.3) & $21(4.8)$ & $434(100.0)$ \\
\hline
\end{tabular}

difference in beer intake between the diary and the other measures with increasing number of cigarettes smoked ( $p$ values for the regression coefficients for smoking were 0.001 for diary versus interview, and $<0.001$ for diary versus interview ${ }_{7}$ ). No other covariates were associated with difference between measures.

The proportion of total abstainers was $29 \%$ for the diary and interview, $28 \%$ for the questionnaire, and $52 \%$ for interview ${ }_{7}$. In week one of the diary $49 \%$ were abstainers, in week two $41 \%$ were abstainers (table 4 ). Only $17 \%$ reported to be abstainers in all four instruments.

Differences between methods, including differences in the proportion of abstainers, may reflect real changes in alcohol intake during pregnancy. Comparing intake during week one of the diary with intake during week 2 (table 4 ), we found that only $44 \%$ of the women reported the same intake during the two consecutive weeks. Comparing interview ${ }_{7}$, which covered the week before starting the
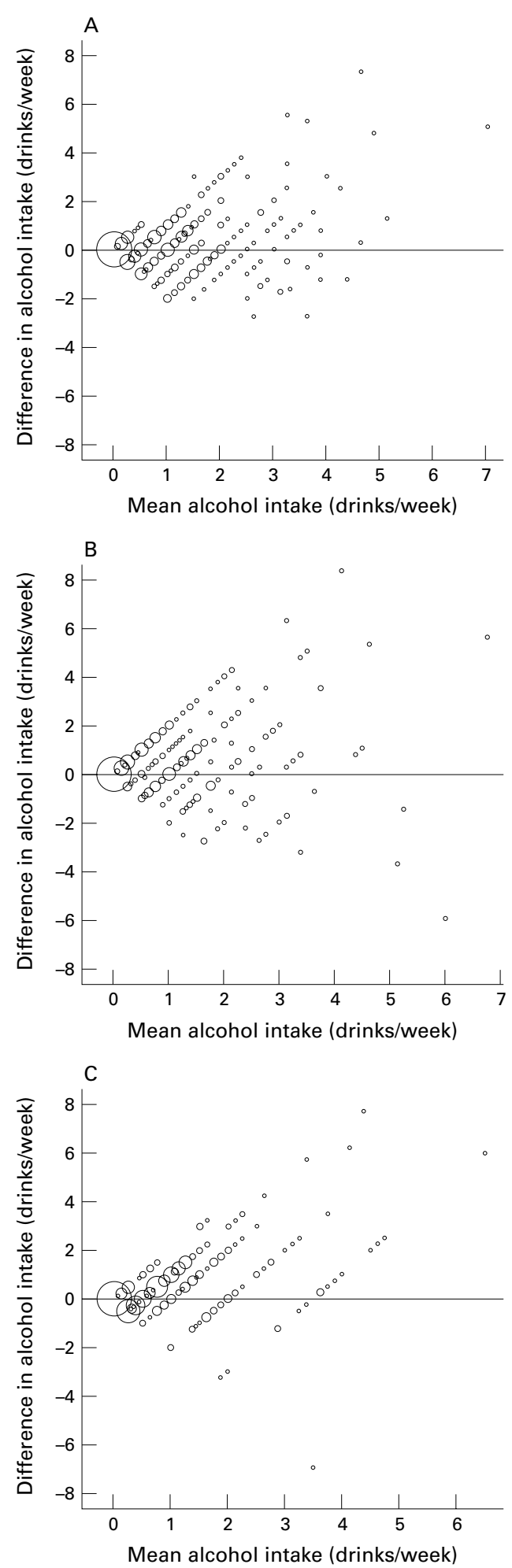

Figure 2 Agreement between different measures of alcohol intake during pregnancy (drinks/week). Differences calculated as: diary minus other method mentioned. Mean alcohol intake calculated as ((diary+other method mentioned)/2). The area of each circle is proportional to the number of women at that point. Aarhus, Denmark, 1998. (A) Diary versus interview (average/week). (B) Diary versus interview, (past week). (C) Diary versus questionnaire.

diary, with week one and week two of the diary $47 \%$ and $40 \%$, respectively, reported similar intake. 


\section{Discussion}

In these data pregnant Danish women reported the highest alcohol intake in a two week diary, slightly lower intake in the interview, and lowest intake in a self administered questionnaire. Mean differences were all less than half a drink/week.

No gold standard has been described for the collection of information on alcohol intake, but it is generally believed that alcohol intake is underreported to some extent. Previous studies among men and non-pregnant women have shown that diaries generally yield higher estimates of alcohol intake than other methods. ${ }^{8-10}$ With respect to prospective interviews and questionnaires the study by Olsen and Frische ${ }^{7}$ showed no substantial differences between methods, whereas Pereira et al found some underreporting in interviews compared with questionnaires. ${ }^{6}$

Some of the differences may be explained by differences in the time interval studied and the specific gestational age at data collection. Previous studies have shown that $70 \%-80 \%$ of pregnant Danish women drink alcohol during pregnancy, ${ }^{18}{ }^{19}$ but most women drink at very low levels and are likely to drink at irregular intervals. As can be seen when comparing week one of the diary with week two, more than half of the women changed their consumption from one week to another. Comparing each week in the diary with interview the same pattern emerged. This seems to suggest that information about intake during one specific week yields information about that particular week, but may not be representative for the overall average intake for a longer period of time because of the week to week variation. Interview $w_{7}$ thus yielded a very high proportion of abstainers compared with the other methods, which tended to reduce the overall mean intake; but at the same time the group of women claiming not to be abstainers in interview ${ }_{7}$ drank more on average than in the other instruments. Compared with interview $_{7}$ week one and week two of the diary each yielded a similar distribution of intake (many abstainers). Yet, the week to week variation reflected in interview $w_{7}$, and each of the weeks in the diary was reduced when using the average measure from the two week diary.

The objective of measuring alcohol intake may be to assess either the distribution of intake in a population or the association between alcohol in pregnancy and adverse pregnancy outcomes. On the basis of a hypothetical study group Verkerk suggested that the best measure for assessing the distribution of alcohol intake in a population would be detailed information on the drinking pattern of the previous week. ${ }^{20}$ In our data interview ${ }_{7}$ yielded the least precise measure of the average distribution. The "true" proportion of total abstainers is likely to be approximately $17 \%$ (those reporting to be abstainers in all methods), and interview 7 thus yielded three times as many abstainers as expected as did each of the weeks in the diary. The two week diary and interview $\mathrm{a}_{\mathrm{a}}$ both yielded very similar distributions. The consumption pattern derived from the questionnaire was more similar to that of the diary and interview $_{\mathrm{a}}$, although a tendency towards underreporting was evident.

This would suggest that in studies focusing on the distribution of alcohol intake among pregnant women, questions on intake should focus either on average intake in general (as in the questionnaire or interview $\mathrm{a}_{\mathrm{a}}$ ), or on a time period of at least two weeks. This would also be the case for studies on adverse pregnancy outcomes that are probably caused mainly by sustained exposure to alcohol such as low birth weight, intrauterine growth retardation, and preterm delivery, as for most women intake during a specific week is not representative for the average intake. On the other hand, for some adverse pregnancy outcomes (for example, malformations and spontaneous abortions) the level of damage is likely to be determined by the peak blood alcohol concentration rather than the average intake. ${ }^{21-23}$ High blood alcohol concentrations are achieved by intake of large volumes of alcohol on a single occasion (binge drinking). In these cases average measures would be insufficient, and ideally specific measures of intake for each week or day in pregnancy would be necessary (interview $_{7}$, or each week or day of the diary).

Avoiding misclassification of drinkers as abstainers may generally increase the likelihood of detecting an effect of alcohol on birth weight. ${ }^{20}$ It is probable that women reporting to be abstainers in the diary or interview ${ }_{7}$ were indeed abstainers during those particular weeks. So for any specific week in pregnancy getting a good measure for the proportion of abstainers may be possible. It seems, however, that such information may not be generalised to cover a longer period of time. This may have implications when studying the association between alcohol and adverse pregnancy outcomes that are most probable caused by sustained alcohol intake over a longer period of time. Hence, one should be cautious when interpreting apparent differences in pregnancy outcome between abstainers and women with a very low alcohol intake. ${ }^{4}$

The context in which the questions were asked may be of significance. In the questionnaire the question on alcohol consumption was mixed with a large number of other questions. Alcohol has thus not appeared to be the target issue, which may have reduced the tendency towards "deliberate" misreporting. The interview on the other hand dealt mostly with various aspects of alcohol in pregnancy, but the main focus was on the women's own attitudes towards drinking rather than level of consumption.

It has been suggested that the respondent's rapport with the interviewer and the extent of confidentiality implied in the procedure are important aspects in an interview situation. ${ }^{24}$ No substantial nor systematic differences were seen between the interviewers with respect to any of the measures. We considered, however, 
KEY POINTS

- Information on current alcohol intake from diaries, interviews, and questionnaires yielded comparable distributions of intake.

- Information on alcohol intake within the past week yielded more abstainers than other methods.

- When studying adverse pregnancy outcomes caused by sustained alcohol exposure average measures from diaries, interviews, or questionnaires may be applied.

- When studying adverse pregnancy outcomes caused by binge-like exposure diaries or intake within the past week might be considered.

that the interview might influence the information given in the diary. We therefore instructed the interviewers that if during the interview a woman asked the interviewer specific questions on the possible hazards of drinking during pregnancy, such questions should be answered by referring to the routine antenatal care or to special information meetings arranged once a month for the participants, who had returned their diaries. By arranging these meetings we attempted to minimise the influence of the interviewer on the information given in the diary.

Still, when repeatedly asking questions on the same issue with a few weeks interval it is possible that the women become more aware of their drinking behaviour. If this were to affect the intake level we would expect the women to decrease their consumption. Yet, the diaries yielded the highest average intake, and only $5 \%$ of the women themselves believed that they had changed their drinking habits after the interview, half of whom had increased their consumption.

\section{Appendix 1 Questions and categories of answers on alcohol intake from interview and questionnaire. Aarhus,} Denmark, 1998.

\section{Interview}

- How many [bottles of] beer did you drink on average per week before you became pregnant? This includes both strong/normal/light, and non-alcoholic beer.

Number of [bottles of] strong beer $\downarrow \downarrow$

Number of [bottles of] normal beer

Number of [bottles of] light beer

Number of [bottles of] non-alcoholic beer $L \perp$

Less than one [bottle of] beer

None

- How many [bottles of] beer do you drink now on average per week? This includes both strong/normal/light, and non-alcoholic beer.

Answer categories same as above

- How many [bottles of] beer have you been drinking within the last 7 days? This includes both strong/normal/light, and non-alcoholic beer.

Answer categories same as above

- How many glasses of wine did you drink on average per week before you became pregnant? This also includes non-alcoholic wine.

Number of glasses of wine

Number of glasses of non-alcoholic wine

Less than 1 glass per week

None $\square$

- How many glasses of wine do you drink now on average per week? This also includes non-alcoholic wine.

Answer categories same as above

- How many glasses of wine have you been drinking within the last 7 days?

Answer categories same as above

- How many glasses of spirits or fortified wine did you drink on average per week before you became pregnant?
How many glasses of spirits or fortified wine do you drink now on average per week?

Answer categories same as above

- How many glasses of spirits or fortified wine have you been drinking within the last 7 days?

Answer categories same as above

- How many bottles of alcopop (soda water with alcohol) did you drink on average per week before you became pregnant? Show bottle [information for interviewer].

Number of bottles

Less than 1 bottle per week

None

- How many bottles of alcopop do you drink now on average per week?

Answer categories same as above

- How many bottles of alcopop have you been drinking within the last 7 days?

Answer categories same as above

\section{Questionnaire}

- How many drinks do you approximately drink per week (one drink is the equivalent of one [bottle of] beer, one glass of wine, or one schnapps)?

30 drinks or more

15-29 drinks

10-14 drinks

5-9 drinks

3-4 drinks

2 drinks

1 drink $\square$

Less than 1 drink

Never drink alcohol 
Appendix 2 Instructions for the two week diary and the first of 14 identical pages (except for day number), each page in the diary representing one day. Aarhus, Denmark, 1998.

How to fill in the diary

DAY 1: DAY

On the following pages we ask you to tick off every time you drink alcohol. We ask you to fill in the forms for a total of 14 days. You may start on any day during the week. Write the day of the week at the top of each page.

- Fill in a new table for each day of the week. Alcohol is usually measured in drinks:

1 light beer

$=1 / 2 \mathrm{drink}$

1 normal beer

$=1$ drink

strong beer

1 glass of wine

$=1 \frac{1}{2}$ drinks

schnapps/glass of spirits

$=1$ drink

1 bottle of alcopop

$=1$ drink

$=1$ drink

$1 / 2$ bottle of wine

$=3$ drinks

1 bottle of wine

$=6$ drinks

- Indicate with a dash / each drink that you drink. If you drink half a bottle of wine you should indicate this with 3 dashes $/ / /$.

- Indicate with the dash / the type of alcohol that you have been drinking: Wine, beer, fortified wine, spirits, alcopops (soda water with alcohol).

- If you drink only half a drink, for example a [bottle of] light beer, write $1 / 2$.

- If you drink $1 \frac{1}{2}$ drinks, for example a [bottle of] strong beer, write $/ 1 / 2$.

\begin{tabular}{|l|l|l|l|l|l|}
\hline & Beer & Wine & $\begin{array}{c}\text { Fortified } \\
\text { wine }\end{array}$ & Spirits & Alcopops \\
\hline Before breakfast & & & & & \\
\hline For breakfast & & & & & \\
\hline In the morning & & & & & \\
\hline For lunch & & & & & \\
\hline In the afternoon & & & & & \\
\hline For supper & & & & & \\
\hline After supper & & & & & \\
\hline & & & & & \\
\hline
\end{tabular}

1 drink $=/ 1 / 2$ drink $=1 / 2$

$\square$ I have not been drinking alcohol today

- If you do not drink alcohol during the day please tick off the box at the bottom of the page "I have not been drinking alcohol today". In this way you and we will know that you have filled in all the pages.

Some studies have assessed whether there might be any difference between the effects of different types of alcohol in pregnancy, and a few of these studies have suggested that beer may be the more harmful. ${ }^{25-27}$ In this study the contribution of each type of alcohol to the total intake was of a similar magnitude for diaries,

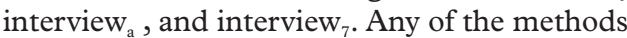
may therefore be applied when investigating subtypes of alcohol.

Different measures of alcohol intake in pregnancy reflect different ways of collecting information. No gold standard has been described, but we found that among women with low and moderate alcohol consumption in pregnancy two week diaries were easy to fill in and not time consuming (approximately 0.5-1 minute needed per day). They yielded a high overall mean intake, a low proportion of abstainers compared with other methods, and a high mean intake among non-abstainers, probably making it the best method of collecting alcohol information in pregnancy, as the distribution of intake may be assessed, studies on adverse pregnancy outcomes that are probably caused mainly by sustained exposure may be carried out using the overall measure, and studies on adverse pregnancy outcomes that are probably caused mainly by binge-like exposure may be carried out using intake during a specific week or even on specific days during gestation. However, when assessing the distribution of intake in a population or when studying adverse pregnancy outcomes that are probably caused mainly by sustained exposure it seems that for pregnant women with low to moderate alcohol intake an average measure from interviews or a simple questionnaire may be applied. A measure of intake for the previous week on the other hand did not seem to be an appropriate measure for the overall distribution of alcohol intake and seems to be a relevant measure only when studying adverse pregnancy outcomes that are most probably caused by binge-like exposure.

Funding: this study was supported by the Faculty of Health Sciences, University of Aarhus, The Danish National Board of Health, and The Danish Research Foundation.

Conflicts of interest: none.

1 Royal College of Obstetricians and Gynaecologists. RCOG uideline: alcohol consumption in pregnancy. London: RCOG, 1996.

2 Kesmodel U. Alkohol og graviditet. [Alcohol in pregnancy]. In Danish with an English abstract]. Ugeskr Laeger 1999;161:4989-94.

3 Passaro KT, Little RE, Savitz DA, et al. The effect of maternal drinking before conception and in early pregnancy on infant birthweight. The ALSPAC Study Team. Avon Longitudinal Study of Pregnancy and Childhood. Epidemiology 1996;7:377-83.

4 Lundsberg LS, Bracken MB, Saftlas AF. Low-to-moderate gestational alcohol use and intrauterine growth retardation, low birthweight, and preterm delivery. Ann Epidemiol 1997; 7:498-508.

5 Windham GC, Fenster L, Hopkins B, et al. The association of moderate maternal and paternal alcohol consumption with birthweight and gestational age. Epidemiology 1995;6: 591-7

6 da Costa Pereira A, Olsen J, Ogston S. Variability of self reported measures of alcohol consumption: implications for the association between drinking in pregnancy and birth weight. F Epidemiol Community Health 1993;47:326-30.

7 Olsen J, Frische G. Comparison between data obtained through questionnaires and interviews: life-style habits of pregnant women. Scand 7 Soc Med 1988;16:49-52.

8 Flegal KM. Agreement between two dietary methods in reported intake of beer, wine and liquor. F Stud Alcohol

9 Poikolainen K, Karkkainen P. Diary gives more accurate information about alcohol consumption than questionnaire. Drug Alcohol Depend 1983;11:209-16. 
10 Uchalik DC. A comparison of questionnaire and selfmonitored reports of alcohol intake in a nonalcoholic monitored reports of alcohol intake in
population. Addict Behav 1979;4:409-13.

11 Anderson P. Alcohol and primary health care. WHO Regional Publications European Series no 64. Copenhagen: WHO Regional Office for Europe, 1996.

12 Maclure M, Willett WC. Misinterpretation and misuse of the kappa statistic. Am $\mathscr{f}$ Epidemiol 1987;126:161-9.

13 Bland JM, Altman DG. Statistical methods for assessing agreement between two methods of clinical measurement. Lancet 1986;1:307-10.

14 Bellach B. Remarks on the use of Pearson's correlation coefficient and other association measures in assessing validity and reliability of dietary assessment methods. Eur 7 Clin Nutr 1993;47 (suppl 2):S42-5.

15 Kesmodel U, Olsen SF. Smoking habits among pregnant danish women: reliability of information recorded after delivery. F Epidemiol Community Health 1999;53:239-42.

16 Byers T, Marshall J, Anthony E, et al. The reliability of dietary history from the distant past. Am $\mathcal{f}$ Epidemiol 1987; 125:999-1011. [Erratum in Am f Epidemiol 1987;126: 1220].

17 Byers T, Marshall J, Fiedler R, et al. Assessing nutrient intake with an abbreviated dietary interview. $A m \mathcal{F}$ Epidemiol 1985;122:41-50.

18 Olsen J, Frische G, Kirchheiner H, et al. Alkoholvaner blandt gravide i Odense 1985-1986. [Alcohol-drinking habits among pregnant women in Odense 1985-1986]. [In Danish with an English abstract]. Ugeskr Laeger 1987;149: $1420-2$.
19 Rubin DH, Krasilnikoff PA, Leventhal JM, et al. Cigarette smoking and alcohol consumption during pregnancy by Danish women and their spouses-a potential source of fetal morbidity. Am f Drug Alcohol Abuse 1988;14: 405-17

20 Verkerk PH. The impact of alcohol misclassification on the relationship between alcohol and pregnancy outcome. Int $\mathcal{F}$ Epidemiol 1992;21 (suppl 1):S33-7.

21 Pennington S, Kalmus G. Brain growth during ethanolinduced hypoplasia. Drug Alcohol Depend 1987;20:279-86.

22 Bonthius DJ, Goodlett CR, West JR. Blood alcohol concentration and severity of microencephaly in neonatal rats depend on the pattern of alcohol administration. Alcohol 1988;5:209-14

23 Zajac CS, Abel EL. Animal models of prenatal alcohol exposure. Int f Epidemiol 1992;21 (suppl 1):S24-32.

24 Babor TF, Stephens RS, Marlatt GA. Verbal report methods in clinical research on alcoholism: response bias and its minimization. F Stud Alcohol 1987;48:410-24.

25 Ogston SA, Parry GJ. EUROMAC. A European concerted action: maternal alcohol consumption and its relation to the outcome of pregnancy and child development at 18 the outcome of pregnancy and child development at 18 months. Results - strategy of analysis and analysis of preg-

26 Sulaiman ND, Florey CD, Taylor DJ, et al. Alcohol consumption in Dundee primigravidas and its effects on outcome of pregnancy. BMf Clin Res Ed 1988;296:1500-3.

27 Kline J, Stein Z, Hutzler M. Cigarettes, alcohol and marijuana: varying associations with birthweight. Int $\mathcal{F}$ Epidemiol 1987;16:44-51.

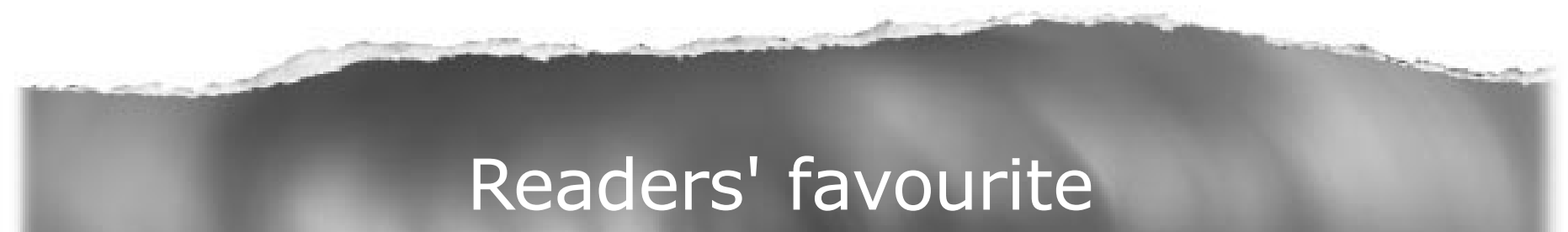

Top 10

Click on the "Top 10" button on the homepage to see which are the best read articles each month

www.jech.com 